\title{
Translation and Adaptation of the Spanish Version of the International Trauma Questionnaire (ITQ) following ITC Guidelines for Translating and Adapting Tests
}

\author{
Carmen Fernández-Fillol ${ }^{1}$, Natalia Hidalgo-Ruzzante ${ }^{1,3}$, Miguel Pérez-García ${ }^{1,2}$ and Julia C. Daugherty ${ }^{1,2}$. \\ Believe Project (CTS-581; Pnínsula Research Group). \\ ${ }^{1}$ The Mind, Brain and Behavior Research Center at University of Granada (Spain). \\ ${ }^{2}$ Dept. of Personality, Evaluation and Psychological Treatment at University of Granada (Spain). \\ ${ }^{3}$ Dept. of Developmental Psychology and Education at University of Granada (Spain).
}

\begin{abstract}
The aim of this report is to present each of the stages taken to adapt the International Trauma Questionnaire (ITQ; Cloitre et al, 2018) to Spanish. Each stage has been carried out rigorously, following the ITC Guidelines for Translating and Adapting Tests Second Edition (2017) published by the ITC (International Test Commission). This guide sets out a series of procedures and standards of good practice to be followed in order to comply with both legal and ethical principles and the standards of good practice established in relation to the use of tests in research.
\end{abstract}

Following these recommendations, the translation and adaptation into Spanish of the ITQ has been carried out by a group of experts in intimate partner violence (IPV) and members of the Believe Project whose interest in translating and adapting this specific measure for PTSD and Complex PTSD lies in their research and to provide this measure to the population to which it may be aimed.

Below, the stages carried out by our team for the translation and adaptation of the Spanish version of the ITQ measure according to ITC Guidelines.

$\underline{\text { Pre-Condition Guidelines }}$

PC-1 (1) Obtain the necessary permission from the holder of the test's intellectual property rights before carrying out any adaptation.

-We have a formal consent via email from Marylene Cloitre, the principal author of the ITQ test, where she authorizes us to perform the Spanish translation/adaptation of the test. This consent was received on January 23th, 2019.

PC-2 (2) Determine whether the amount of overlap between the definition and content of the construct measured by the test and the item content in the populations of interest is sufficient for the intended use (or uses) of the scores.

-The researchers in charge of the adaptation and translation of the test are familiar with the construct and have previous experience in the evaluation of the target population. As mentioned, the group of experts that take part in the Spanish adaptation of the measure are part of the Believe Project. These researchers are conducting psychological and neuropsychological assessments with victims of IPV and the evaluators are in constant contact with the target population. As such, the evaluators are aware of the heterogeneity of this population and have ensured that the content of the test can be answered by the whole target population. 
PC-3 (3) Minimize the influence of any cultural and linguistic differences that are irrelevant to the intended uses of the test in the populations of interest.

-The translators, in addition to being involved in the research and evaluation of the target population, are native speakers of the target language and culture (Spanish). Further, this team also includes a native English-speaker from the United States who has resided in Spain for 7 years, giving her a greater knowledge and proximity about the target culture.

\section{$\underline{\text { Test Development Guidelines }}$}

TD-1 (4) Ensure that the translation and adaptation processes consider linguistic, psychological and cultural differences in the intended populations through the choice of experts with relevant expertise.

-As previously mentioned, it is imperative that translators have experience with the content of the test and in the evaluation principles in order to comply with this point. The translators, in addition to being knowledgeable about test content and application, are native speakers of the target language and the source language and have in-depth knowledge about the culture to which the test has been adapted. Furthermore, all evaluators live in the same area in which they carry out the evaluations. The team experts in charge of producing the Spanish version are as follows:

-Miguel Pérez-García (PhD in Psychology at University of Granada) is a Professor of Clinical Neuropsychology in the Dept. of Personality, Evaluation and Psychological Treatment at University of Granada and researcher at the Mind, Brain and Behavior Research Center (CIMCYC) at the same university. He is also responsible for the Andalusian Regional Government's research group "Neuropsychology Applied to Children, Adults and the Elderly" (CTS-581). He specializes in the neuropsychology of intimate partner violence, the neurodevelopment of children exposed to violence, posttraumatic stress disorder and the validation of instruments for other cultures.

-Natalia Hidalgo-Ruzzante (PhD in Psychology at University of Granada) is a Professor in the Dept. of Developmental Psychology and Education and a researcher at the CIMCYC. She is specialized in the evaluation of cognitive impairment and the psychological treatment of female victims of intimate partner violence, as well as child development in situations of vulnerability and violence. In addition, she studies the effects of culture on psychological and neuropsychological evaluation.

-Julia C. Daugherty (PhD in Psychology at University of Granada) is a researcher at the University of Granada and a member of the research group Neuropsychology Applied to Children, Adults and the Elderly. She is expert in neuropsychology and intimate partner violence and at the same time, she has a research trajectory in the topic of cultural bias in neuropsychological performance.

-Carmen Fernández-Fillol (PhD student in Psychology at University of Granada) is a researcher at University of Granada and a member of the research group Neuropsychology Applied to Children, Adults and the Elderly. She is developing her thesis on posttraumatic stress disorder, complex posttraumatic stress disorder and continuous stress in relation to other psychological and neuropsychological impairments of intimate partner violence.

TD-2 (5) Use appropriate translation designs and procedures to maximize the suitability of the test adaptation for the intended populations.

-A back translation design was used to verify the target version created through double translation and reconciliation by a panel of experts. The stages followed in this process are the following:

1‥ Translation/ adaptation of the original ITQ English version to Spanish. It was completed on January 29th, 2019 by Carmen Fernández Fillol. This draft can be consulted by clicking on this hyperlink directed to Appendix I. 
$2^{\circ}$. Back translation of the Spanish version into English. It was completed on February 4th, 2019 by Julia C. Daugherty. To consult this draft, click on Appendix II.

3 . Consensus to make the final version of the Spanish version based on previous versions. It was made on February 21th, 2019 by Carmen Fernández Fillol and Julia C. Daugherty. To consult this draft, click on Appendix III.

$4^{\circ}$. Last revised draft of the Spanish version by third judges to verify the consensus by the whole group of experts. It was completed on February 25th and on March 5th, 2019 by Miguel PérezGarcía and Natalia Hidalgo-Ruzzante. In this phase, the experts emphasized the fulfillment of the cultural adaptation test for the target population. This is the final version of the ITQ measure in Spanish and can be found by clicking on Appendix IV or on the International Trauma Consortium website.

5o. Final reading of the final Spanish version reading by three people who are not experts on the subject and who have had intermediate studies on March 12th, 2019.

TD-3 (6) Provide evidence that the test instructions and item content have similar meaning for all intended populations.

-The test instructions have also been translated and adapted by our team. As noted above, we have complied with the recommendation to use reviewers who are native to the local culture and native speakers of the original language to evaluate the translation/ adaptation of the test.

TD-4 (7) Provide evidence that the item formats, rating scales, scoring categories, test conventions, modes of administration, and other procedures are suitable for all intended populations.

-We have ensured that the test items translated to Spanish are clear enough for all respondents to provide honest and consistent answers. In addition, we have made sure that the original format is respected and that the respondents have a simple way of completing to the tests.

TD-5 (8) Collect pilot data on the adapted test to enable item analysis, reliability assessment and smallscale validity studies so that any necessary revisions to the adapted test can be made.

-Pilot data collection will be possible as soon as the Spanish version is approved. We currently have access the target population and are in the process of evaluating them as a part of the Believe Project.

In summary, the entire process may be summarized as follows:

Table 1

Detailed information on stages taken in the Pre-Condition phase

\begin{tabular}{|c|c|c|c|c|}
\hline Phase & Stage & Description & Date & Responsible \\
\hline \multirow[t]{3}{*}{ Pre-Condition } & PC-1 & $\begin{array}{c}\text { Obtain the necessary } \\
\text { permission from the holder. }\end{array}$ & $\begin{array}{c}\text { January, } 23^{\text {th }} \\
2019\end{array}$ & Carmen Fernández-Fillol \\
\hline & PC-2 & $\begin{array}{l}\text { Overlap in definition, test and } \\
\text { item in target population. }\end{array}$ & & $\begin{array}{l}\text { Carmen Fernández-Fillol } \\
\text { Julia C. Daugherty } \\
\text { Natalia Hidalgo-Ruzzante } \\
\text { Miguel Pérez-García }\end{array}$ \\
\hline & PC-3 & $\begin{array}{c}\text { Minimize the influence of any } \\
\text { cultural and linguistic } \\
\text { differences. }\end{array}$ & & $\begin{array}{l}\text { Carmen Fernández-Fillol } \\
\text { Julia C. Daugherty }\end{array}$ \\
\hline
\end{tabular}


Table 2

Detailed information on stages taken in the Test Development phase

\begin{tabular}{|c|c|c|c|c|}
\hline Phase & Stage & Description & Date & Responsible \\
\hline \multirow[t]{8}{*}{ Test Development } & TD-1 & $\begin{array}{l}\text { Ensure that the translation and } \\
\text { adaptation processes consider } \\
\text { linguistic, psychological, and } \\
\text { cultural differences in the } \\
\text { intended populations through } \\
\text { the discretion of experts with } \\
\text { relevant expertise. }\end{array}$ & & $\begin{array}{c}\text { Carmen Fernández-Fillol } \\
\text { Julia C. Daugherty } \\
\text { Natalia Hidalgo- } \\
\text { Ruzzante } \\
\text { Miguel Pérez-García }\end{array}$ \\
\hline & TD-2 & $\begin{array}{l}\text { Use appropriate translation } \\
\text { designs and procedures. }\end{array}$ & & \\
\hline & & $\begin{array}{l}\text { Translation/adaptation of the } \\
\text { original ITQ English version to } \\
\text { Spanish (Appendix I). }\end{array}$ & $\begin{array}{c}\text { January } 29^{\text {th }} \\
2019\end{array}$ & Carmen Fernández-Fillol \\
\hline & & $\begin{array}{l}\text { Back translation of the Spanish } \\
\text { version into English (Appendix } \\
\text { II). }\end{array}$ & $\begin{array}{c}\text { February } 4^{\text {th }}, \\
2019\end{array}$ & Julia C. Daugherty \\
\hline & & $\begin{array}{l}\text { Consensus to make the final } \\
\text { draft of the ITQ Spanish } \\
\text { version (Appendix III). }\end{array}$ & $\begin{array}{c}\text { February } 21^{\text {th }} \\
2019\end{array}$ & $\begin{array}{c}\text { Carmen Fernández-Fillol } \\
\text { Julia C. Daugherty }\end{array}$ \\
\hline & & $\begin{array}{l}\text { Last revised draft of the } \\
\text { Spanish version by third } \\
\text { judges. Final version of the } \\
\text { ITQ in Spanish (Appendix IV). }\end{array}$ & $\begin{array}{l}\text { February } 25^{\text {th }} \\
2019 \text { and March } \\
5^{\text {th }}, 2019\end{array}$ & $\begin{array}{l}\text { Natalia Hidalgo- } \\
\text { Ruzzante } \\
\text { Miguel Pérez-García }\end{array}$ \\
\hline & TD-3 & $\begin{array}{l}\text { Provide evidence that the test } \\
\text { instructions and item content } \\
\text { have a similar meaning for all } \\
\text { intended populations. }\end{array}$ & & $\begin{array}{l}\text { Carmen Fernández-Fillol } \\
\text { Julia C. Daugherty } \\
\text { Natalia Hidalgo- } \\
\text { Ruzzante } \\
\text { Miguel Pérez-García }\end{array}$ \\
\hline & TD-4 & $\begin{array}{l}\text { Provide evidence that the item } \\
\text { format, rating scales, scoring } \\
\text { categories, test conventions, } \\
\text { modes of administration, and } \\
\text { other procedures are suitable } \\
\text { for all intended populations. }\end{array}$ & & $\begin{array}{l}\text { Carmen Fernández-Fillol } \\
\text { Julia C. Daugherty } \\
\text { Natalia Hidalgo- } \\
\text { Ruzzante } \\
\text { Miguel Pérez-García }\end{array}$ \\
\hline
\end{tabular}




\section{References}

Cloitre, M., Shevlin M., Brewin, C.R., Bisson, J.I., Roberts, N.P., Maercker, A., Karatzias, T., Hyland, P. (2018). The International Trauma Questionnaire: development of a self-report measure of ICD-11 PTSD and complex PTSD. Acta Psychiatrica Scandinavica, 138(6), 536-546.

International Test Commission, ITC. (2018). ITC Guidelines for Translating and Adapting Tests (Second Edition), International Journal of Testing, 18:2, 101-134.

\section{Interesting Websites}

Believe Project: https://projectbelieve.info/en/

The Mind, Brain and Behavior Research Center: https://cimcyc.ugr.es/?lang=en

Miguel Pérez-García (PhD): https://orcid.org/0000-0003-4775-7556

Natalia Hidalgo-Ruzzante (PhD): http://orcid.org/0000-0002-9952-9478

Julia C. Daugherty (PhD): https://orcid.org/0000-0002-1221-4394

Carmen Fernández-Fillol (PhD student): https://www.researchgate.net/profile/Carmen Fernandez Fillol 